\title{
A Pedagogia do Oprimido como referência para a EJA e para a Educação Popular
}

\section{Pedagogy of the Oppressed as reference for the Young and Adult Education and Popular Education}

\section{La Pedagogía del Oprimido como referencia para la EPJA y para la Educación Popular}

\author{
DANILO R. STRECK ${ }^{1}$ \\ Carolina Schenatto da Rosa 1 \\ ${ }^{1}$ Universidade do Vale do Rio dos Sinos (Unisinos), São Leopoldo, RS, Brasil.
}

\begin{abstract}
RESUMO
$\mathrm{O}$ artigo tem por objetivo problematizar porque a Pedagogia do Oprimido é uma referência permanente para a Educação Popular e para a Educação de Jovens e Adultos. A atualidade da obra foi analisada a partir de três dimensões: o popular na educação, o pensar crítico e a revolução cultural. As análises evidenciam que, apesar da Educação de Jovens e Adultos estar longe de cumprir com seu papel reparador no Brasil, o caráter dialógico e humanizador da pedagogia freireana continua presente nas práticas pedagógicas. A Pedagogia do Oprimido pode ser uma referência tanto como uma orientação ético-política quanto uma matriz teórico-prática.
\end{abstract}

Palavras-chave: Paulo Freire. Pedagogia do Oprimido. EJA. Educação Popular.

\begin{abstract}
This paper aims to understand the reasons why Pedagogy of the Oppressed is a permanent reference for Popular Education and Youth and Adult Education. The relevance of the book for today was analyzed in three dimensions: the popular in education, the critical thinking and cultural revolution. This leads us to believe that, despite Youth and Adult Education in Brazil being far from complying with its restorative purpose, the dialogical and humanizing feature of Freire's pedagogy remains present in the pedagogical practices. Pedagogy of the Oppressed may be a reference as much for ethical-political direction as a practical-theoretical matrix.
\end{abstract}

Keywords: Paulo Freire. Pedagogy of the Oppressed. Youth and Adult Education. Popular Education.

\section{RESUMEN}

El artículo tiene por objetivo problematizar porque la Pedagogía del Oprimido es una referencia permanente para la Educación Popular y para la Educación de Jóvenes y Adultos. La actualidad de la obra fue analizada a partir de tres dimensiones: el popular en la educación, el pensar crítico y la revolución cultural. Los análisis evidencian que, a pesar de la Educación de Jóvenes y Adultos estar lejos de cumplir con su papel reparador en Brasil, el carácter dialógico y humanizador de la pedagogía freireana continúa presente en las prácticas pedagógicas. La Pedagogía del Oprimido puede ser uma referencia tanto para la orientación ético-política quanto como una matriz teórico-práctica. Palabras clave: Paulo Freire. Pedagogía del Oprimido. EPJA. Educación Popular. 


\section{INTRODUÇÃO}

Estranho e paradoxal que depois de 50 anos, Pedagogia do oprimido e seu autor, Paulo Freire, estejam retornando ao cenário político-pedagógico em meio a controvérsias e ataques. Acreditamos que nem o livro, nem Paulo Freire e sua obra necessitem de alguma justificativa para continuarem existindo. Guardiões de uma ortodoxia freireana são dispensáveis diante de uma obra que, literalmente, conquistou o mundo da educação como poucas obras dos últimos tempos. Melhor do que "defender" Paulo Freire de ataques muitas vezes com pouco fundamento e informação é buscar compreender porque Pedagogia do oprimido se tornou tão importante para tanta gente ao redor do mundo e porque, meio século depois, ainda é objeto de estudos e ainda motiva a escrita de artigos.

Uma razão pode ser encontrada no fato de haver uma identificação com um posicionamento ético-políticopedagógico com os oprimidos. Muito já se debateu sobre a categoria oprimido e, com certeza, muito ainda será debatido uma vez que os oprimidos, como sujeitos individuais e coletivos, têm muitos rostos e ocupam diferentes lugares em distintos contextos sociais e históricos.

Os oprimidos da década de 1960 se debatiam com situações-limite diferentes daquelas enfrentadas pelos de hoje; as condições objetivas e subjetivas da opressão eram outras, mas elas continuam existindo e enquanto elas existirem vão continuar surgindo pedagogias dos oprimidos e a obra de Paulo Freire será lembrada como uma referência. Talvez alguns incautos queiram copiá-la, mas esses podem ser lembrados de que o autor já preveniu que ele não queria ser copiado, mas reinventado.

Outra razão é que se trata de um livro que combina uma experiência educativa real e concreta com rigor acadêmico. Pedagogia do oprimido reflete uma prática educativa de alguém que ousou "cruzar a linha" e compreender como poderia ser a educação vista na perspectiva dos oprimidos. Por isso, não é uma pedagogia para eles, mas forjada com eles na sua luta por conhecer e mudar o seu mundo (FREIRE, 2017). É isso que tornou o livro tão perigoso quando surgiu e o faz seguir sendo perigoso ao longo dos tempos, enquanto houver quem busque questionar e subverter uma ordem social injusta e opressora.

Ainda, temos que considerar que essa obra é uma síntese não apenas do trabalho de Freire para a alfabetização libertadora, mas, também, das transformações na educação ocidental e das discussões em torno dela ao longo da década de 60. Usando a metáfora empregada por Freire (2018), Pedagogia do oprimido emerge de tramas, tramas culturais, políticas e históricas que extrapolam o campo da experiência do autor e tornam-se universais pela sua capacidade de dialogar com outras tramas, com novas ideias e histórias. E é, justamente, essa capacidade de dialogar com distintas tramas da história que apontamos como outra possível razão tanto para a popularização da obra, quanto para sua atualidade.

Tendo em vista esse horizonte dialógico, a pergunta que gostaríamos de abordar neste texto é porque e de que maneira a Pedagogia do oprimido é uma referência permanente e consolidada para a educação popular (EP) e para a educação de jovens e adultos (EJA). Ao elaborar este questionamento, partimos do pressuposto de que, ao menos historicamente, na América Latina, a Educação Popular nasce no âmbito da então Educação de Adultos. Tanto assim que a própria experiência pedagógica de Freire é inicialmente realizada junto a adultos, sendo esse um dos motivos pelos quais durante muito tempo se discutiu se a sua pedagogia poderia ser "aplicada" em escolas, com crianças e adolescentes.

Nesse sentido, cabe salientar que sabemos que o simples fato de ser "conhecida" ou citada não aufere potência à obra. $\mathrm{O}$ reconhecimento dela não está expresso no uso indiscriminado e descontextualizado das ideias, que, à medida em que se popularizam, são generalizadas e sectarizadas. A relação com Pedagogia do oprimido, nesse contexto, não é diferente daquela que se estabelece com outros clássicos da educação, como o Emílio de Rousseau ou a Didática Magna de Comenius. São obras que, de tão (re)conhecidas, são desistoricizadas e pouco lidas com a devida rigorosidade.

Essa é uma das peculiaridades de um clássico, como diz Ítalo Calvino (1993): todos assumem que o leram e, por isso, quase sempre "relendo" o livro; ele já é parte do imaginário, já está no senso comum e, por estar na "boca do povo", todos já ouviram falar, bem ou mal. Dessa forma, pode-se concordar ou discordar, endeusar ou diabolizar, mas é difícil deixar de reconhecer a sua existência para além das preferências individuais.

Considerando essas razões, nossa proposta para as páginas que seguem é mais uma releitura de Pedagogia do oprimido a partir da EJA e da EP. Analisaremos a atualidade de tramas que acompanharam o clássico em diversas releituras em seus 50 anos de história. Para tanto, organizamos nossas ideias baseados em três dimensões que consideramos essenciais para a compreensão da obra: o popular na educação; o pensar crítico e a revolução entendida como transformação radical da sociedade e de conceber a educação. Na primeira dimensão, discutiremos a pesquisa realizada pela Campaña Latinoamericana por el derecho a la Educación (CLADE), salientando o papel da Pedagogia do oprimido na articulação entre a EJA e a Educação Popular. Em um segundo momento, problematizamos a urgência do pensar crítico, um dos 
elementos centrais da obra analisada, em um contexto no qual as ideias tornam-se cada vez mais sectarizadas e a educação torna-se um "alvo". Por fim, em contraposição a essa sectarização, apresentamos alguns caminhos, a partir da Pedagogia do oprimido, para a revolução na prática e na concepção da educação de jovens e adultos.

\section{O POPULAR NA EDUCAÇÃo: O QUE DIZEM AS VOZES DA EJA}

Ainda que Paulo Freire não defina o que entende pelo termo "educação popular" na Pedagogia do oprimido, desde as suas "primeiras palavras" o autor ajuda-nos a compreender o significado desta expressão ao explicar que as origens de sua reflexão não são meramente exposições teóricas e, tampouco, um mero relato de uma prática educativa que desenvolvera no Brasil anos antes. Para o autor, este livro é uma reflexão sobre as situações concretas que vivenciou, sobre as "reações de proletários, camponeses ou urbanos, de homens de classe média" a uma proposta coletiva de libertação e essa proposta é, em si, o que compreendemos por educação popular. Uma educação cujo princípio é o amor, o respeito, o diálogo, a esperança, a humildade e a simpatia. (FREIRE, 2017, p. 33)

Talvez a contribuição mais importante de Pedagogia do oprimido para pensarmos a educação popular seja, justamente, a demarcação de uma epistemologia baseada nessa pluralidade de princípios. Ou seja, a proposta do autor não é criar ou validar uma nova teoria educativa; pelo contrário, ele buscou a convergência de distintas correntes de pensamento. Essa convergência é, na realidade, o princípio dialógico para o qual Freire dedica um capítulo inteiro de sua obra. É por meio desse diálogo que ele conseguiu " [...] criar laços, interligar as categorias da história, da política, da economia, de classe, gênero, etnia, pobres e não-pobres". (GADOTTI, 2007, p. 23)

Em suas tramas o autor mostra-nos que toda a educação que busca autonomia e liberdade é popular. É popular quando se faz na prática da investigação dos temas geradores, daquela temática capaz de mobilizar as pessoas (crianças, jovens e adultos) para conhecer e mudar o seu mundo. É popular porque, além de interdisciplinar, é intercultural.

A Pedagogia do oprimido é um exemplo de articulação entre tipos de conhecimento distintos e entre áreas de conhecimento distintas para a construção de uma teoria coerente tanto do ponto de vista metodológico e científico, quanto do ponto de vista ideológico e prático. É coerente no sentido de articular ideias, relacionar tramas para dar conta de explicar uma realidade, não para justificar o acerto ou o erro de determinada teoria (seja o personalismo, o marxismo ou a fenomenologia, por exemplo). Freire não se coloca como um seguidor de uma corrente ou teoria, ele junta autores de diversas áreas e correntes para sistematizar uma experiência que reuniu especialistas de várias áreas; e mais do que isso: ele sistematizou uma experiência na qual os próprios educandos foram sujeitos na leitura de seu mundo.

Essa perspectiva inspirou ou deu suporte para o desenvolvimento de práticas educativas dialógicas e populares ao redor de todo o mundo. Na América Latina, é possível destacar, dentre as iniciativas destinadas a qualificar as políticas educacionais para jovens e adultos, a Campaña Latinoamericana por el derecho a la Educación. A CLADE é uma rede formada por organizações da sociedade civil que atua em prol da educação pública humanizada, transformadora, laica e gratuita para todas e todos os latino-americanas/os ao longo de suas vidas. (CLADE, 2017). A CLADE é um exemplo, em termos metodológicos e epistemológicos, do quanto Freire influenciou a educação latino-americana e promoveu a articulação entre as diferentes formas de pensar e exercitar a educação popular.

Um dos resultados desta articulação da CLADE em prol das políticas de EJA é o projeto "Ampliando voces: miradas y propuestas para la Educación de Personas Jóvenes y Adultas (EPJA) en la perspectiva de sus sujetos", proposta gestada durante a Reunión Regional de Seguimiento de la CONFITEA VI, realizada no México em 2011. A ideia, elaborada em parceria com o Consejo de Educación de Adultos de América Latina (CEAAL), com a Red de Educación Popular entre Mujeres (REPEM) e com o Consejo Internacional de Educación de Personas Adultas (ICAE), nasceu como uma alternativa para reverter a ausência das vozes e das perspectivas de educadoras/es e educandas/os nos espaços de deliberação e escutou professores/as e alunas/os, com idades entre 13 e 83 anos, de diferentes países da América Latina. (ROSA, 2017).

Desenvolvido entre 2011 e 2017 , o projeto reuniu respostas de 340 educandas/os e 137 professoras/es a respeito das práticas e políticas educativas desenvolvidas em países latino-americanos, que foram sintetizadas em um relatório final. Há muito da Pedagogia do Oprimido nesse processo, que buscou, por meio de uma plataforma online, conectar o continente através de uma experiência metodológica muito próxima aos círculos de cultura. Na plataforma, que permanece aberta para a escuta e participação de pessoas jovens e adultas inseridas em espaços e em processos de formação e/ou que não concluíram sua trajetória educativa, é possível ler testemunhos, ver vídeos, localizar textos, publicações e notícias sobre a EJA na América Latina. Ali se compartilham experiências, se aprende e se ensina. 
Um dos primeiros passos da campanha foi perguntar para alunos e alunas "o que desejam com o processo educativo e por qual razão o buscam"; ou seja, foi procurar ouvir o que querem os alunos da EJA, por qual razão retornaram e permanecem estudando. A partir do diagnóstico preliminar, a CLADE criou eixos de trabalho que guiaram o processo de escuta e a organização de materiais. Isso é, na prática, a teoria da ação dialógica. Essa campanha buscou compreender a EJA no contexto latinoamericano e transformá-la por meio da co-laboração e da pronúncia. "A co-laboração, como característica da ação dialógica, que não pode dar-se a não ser entre sujeitos, ainda que tenham níveis distintos de função, portanto, de responsabilidade, somente pode realizar-se na comunicação", disse Freire (2017, p. 228). Os meios pelos quais essa comunicação ocorre se transformaram, as tecnologias de informação e comunicação permitiram que sujeitos de diferentes países pronunciassem e problematizassem o mundo, promovendo e evidenciando que, apesar de existirem muitas EJAs, é possível perceber traços comuns de união, organização e síntese cultural.

A esse respeito, destacamos alguns aspectos presentes no relatório que nos ajudam a perceber essas três características da ação dialógica. O primeiro deles é a percepção dos sujeitos que participaram da campanha sobre a educação. As pessoas que responderam à Campanha da CLADE (2017), frequentemente definiram a educação como uma forma de superação, de crescimento pessoal e intelectual que lhes possibilitou serem melhores para seus filhos, para a sociedade e para si mesmas. $\mathrm{Ou}$ seja, a educação é vista como uma possibilidade de tornarse humano junto com o outro e, assim, permanentemente, transformar-se em um ser humano melhor. A resposta dada por esses sujeitos ilustra, em termos freireanos, a educação como prática para a liberdade; ela anuncia a prática pedagógica problematizadora e desalienadora na busca do ser mais.

Outro aspecto curioso é pensar que essa educação, que os torna mais humanos, melhores, não aparece, nas respostas, descolada de uma educação profissional (ainda que não seja a preocupação primeira dos sujeitos entrevistados). Parece-nos que, no caso dos alunos ouvidos pela campanha, a educação profissional não é compreendida como aquela que "prepara para o mundo do trabalho", o mundo dado. Na compreensão das vozes da EJA, a dimensão profissional aparece como o exercício consciente do trabalho enquanto ato criador, como desenvolvimento humano; ela é o resultado de um exercício que, seja prioritariamente físico ou intelectual, jamais é mecânico.

Um terceiro aspecto que consideramos relevante para pensarmos nas tramas que aproximam a EJA e a EP e que está diretamente relacionado com a concepção de educação e de trabalho das vozes que compõem a pesquisa da CLADE - é a relação entre a educação de jovens e adultos e os movimentos sociais. Quase $1 / 3$ dos estudantes entrevistados frequentavam classes ligadas a movimentos sociais, espaços onde o legado da Educação Popular, fortemente marcado pela a capacidade de mobilização e organização e pela vontade política de transformar a própria realidade, se mantém mais vivo. É o empenho para a união dos oprimidos, para que se reconheçam como sujeitos "melhores para a sociedade, para seus filhos e para si mesmos". Nestes espaços educativos se busca a superação de um ensino compensatório, de uma política que prevê a manutenção das estruturas e leva a ser-paraoutro.

No prefácio do livro Pedagogia do Oprimido (2017), o professor Ernani Maria Fiori sintetiza a concepção freireana de ser-para-si na seguinte afirmação: “[...] os homens [as pessoas] humanizam-se, trabalhando juntos para fazer do mundo, sempre mais, a mediação de consciências que se coexistenciam em liberdade" (FREIRE, 2017, p.22). Essa mediação de consciências, em uma sociedade tão plural quanto a nossa, pode ser expressa pela noção de síntese cultural, que é uma característica facilmente percebida na metodologia da Campanha.

No entanto, não é apenas na metodologia que a CLADE enfatiza a importância da síntese cultural para as políticas e práticas de EJA na América Latina. "A síntese cultural não nega as diferenças entre uma visão e outra, pelo contrário, se funda nelas. O que ela nega é a invasão de uma pela outra. O que ela afirma é o indiscutível subsídio que uma dá a outra". (FREIRE, 2017, p.249) É isso que Freire diz em uma das últimas páginas do livro. E é isso que percebemos na proposta da CLADE: a reunião de distintas perspectivas sobre a EJA para que se subsidiem, para que compartilhem experiências e somem esforços. Por exemplo, é o reconhecimento da relevância da síntese cultural para a EJA que faz com que professores, pesquisadores, alunos e militantes se reúnam para partilhar ideias no portal da Campanha.

\section{O PENSAR CRÍTICO: RESISTÊNCIA E DIÁLOGO FRENTE A SECTARIZAÇÃo}

Se, por um lado, Pedagogia do Oprimido nos possibilita a leitura dos inéditos viáveis, isto é, a percepção da "consciência possível" nas vozes da EJA como potencialmente libertadoras, por outro lado, o livro nos permite perceber, em nosso contexto, algumas situaçõeslimite que necessitamos confrontar, situações que são úteis para entendermos porque o ciclo de reprodução da opressão se repete, porque manifestações antagônicas à libertação crescem no mundo. Essas contradições do 
mundo, quando conscientizadas, ou seja, confrontadas pela "educação verdadeira", como lembra o professor Fiori (2017, p. 25), possibilitam-nos "pensar e viver a "educação como prática de liberdade'". Essa educação como prática de liberdade, cuja matriz é a cultura popular, permitiu resistir e (re)existir ao longo dos séculos de domínio colonial.

O contexto no qual Freire escreveu Pedagogia do oprimido, como já mencionamos, é um ambiente de resistência, de profundas transformações em diferentes lugares do mundo; é a conjuntura de efervescência dos movimentos estudantis, movimentos de rebelião que questionavam desde a relação autoritária entre professores e alunos até as burocracias inoperantes e a civilização do consumo. Movimentos que, na percepção de Freire, tinham como problemática central a questão da humanização. Pode-se ver a importância dada pelo autor a esses movimentos no fato de ele dedicar-lhes a primeira nota de rodapé explicativa do livro ${ }^{1}$, na qual ressalta a preocupação dos movimentos, sobretudo dos jovens, em torno dos seres humanos enquanto seres no mundo e com o mundo (FREIRE, 2017, p. 39).

Naquela época vivia-se um momento de redescoberta similar ao que vivemos hoje: por um lado, as pautas das minorias, que em realidade são maiorias, despertam consciências e ocupam espaços nas agendas globais; e por outro, setores historicamente opressores passam a se organizar e buscar espaço dentro destas agendas, por meio da criminalização e destituição da luta por direitos sociais. Acontece que, apesar de vivermos um momento de similar "despertar de consciências", o mundo mudou e essas mudanças têm afetado diretamente o processo de ad-miração, de conscientização, dentro e fora da escola.

As tecnologias digitais mudaram as formas de comunicação e interação no mundo e com o mundo, as relações de trabalho são diferentes, as escolas não são mais as mesmas... e em especial na última década, a forma como interpretamos a realidade, como recebemos as informações e as significamos sofreu uma profunda ruptura em função das redes sociais e suas "bolhas digitais", cujo potencial para propagação de notícias falsas tem tornado turvas e embaralhadas as "leituras" de mundo. Se antes a internet era a terra da pluralidade, do livre acesso e da democracia, agora, por meio da popularização das redes sociais como espaço primeiro de interação e informação, as relações ficam cada vez mais sectarizadas. Essa sectarização - e seus impactos na educação - não é uma exclusividade do contexto brasileiro.

\footnotetext{
${ }^{1}$ Ao longo das reedições do livro foram acrescidas notas de rodapé na obra, de modo que a numeração destas varia. Essa é uma das características intrínsecas desta "obra viva" e da própria práxis freireana: sempre que revisitada e revisada é transformada. Até a edição utilizada neste texto a nota segue sendo a primeira do capítulo 1 .
}

Michel Apple (2003; 2005; 2015), por exemplo, tem se dedicado a compreender, a partir de uma perspectiva internacional, o avanço e os reflexos da agenda neoliberal e do discurso política e ideologicamente neoconservador na educação. Suas análises, que abordam o contexto norteamericano, inglês, escandinavo e, mais recentemente, brasileiro, levaram o autor a defender que as pedagogias da corrente crítica, que se opõem ao modelo políticoideológico neoliberal e conservador, não podem se sustentar apenas como uma crítica na ordem do discurso, enquanto retórica no campo teórico. É preciso que esse campo crítico desenvolva, de forma prática, alternativas para a transformação da realidade, desenvolva junto aos movimentos sociais e ao senso comum alternativas contrahegemônicas que, de fato, promovam transformações sociais, culturais e ideológicas na educação a partir das práticas pedagógicas.

No nosso caso, o autor sugere que o avanço das formas político-ideológicas neoliberais na educação resulta em "[...] uma perda parcial da memória coletiva das lutas radicais e dos movimentos na educação, que tem uma história muito extensa no Brasil" (APPLE, 2015, p. 608). Ou seja, nós nos esquecemos das práticas libertadoras, da educação problematizadora. No exercício de uma política e de uma prática educacional que reproduz o senso comum, nos esquecemos do que Paulo Freire escreveu, do significado e do resultado das experiências que sistematizou.

É neste contexto de "esquecimento" que emergem discursos contra Paulo Freire e a favor de uma "escola sem partido", na mesma medida em que proliferam espaços educacionais que usam como slogan justamente a "neutralidade", a "ausência ideológica" na sua educação. Esse é um dos pontos que gostaríamos de discutir para compreender a atualidade da Pedagogia do Oprimido não apenas para a EJA, mas para todos os níveis e modalidades de educação: a necessidade de leitura do mundo e o reconhecimento das formas de opressão e de dominação.

A não neutralidade - política e ética - da educação é uma premissa básica em Paulo Freire. Trata-se de uma não neutralidade que ultrapassa os limites partidários ou de posições e funções nas quais circunstancialmente nos encontramos. Por isso, parece-nos que a discussão sobre a "escola sem partido" faz muito pouco sentido.

Vivendo em um dos países onde os níveis de desigualdade continuam a estar entre os mais elevados do mundo e onde a educação ajuda a reproduzir esta desigualdade, a leitura deste mundo continua sendo uma tarefa fundamental. Por isso, proibir professores e alunos de problematizar a realidade, de exercitar a curiosidade é o oposto de qualquer perspectiva moderna de educação e é, a própria proibição, uma imposição autoritária de 
sectarização do pensamento e das ações dos próprios professores, alunos e de toda a comunidade escolar.

Importante lembrar que, para Freire, a sectarização é sempre irracional, castradora e baseada em uma falsa realidade, como podemos perceber tanto nas falas da parlamentar eleita que estimulou alunos a filmarem e denunciarem professores que façam "doutrinação ideológica" , quanto nas falas do pai de aluno que escreveu um texto de opinião para um jornal sugerindo que "[...] dentro da mais humilde escola pública municipal ou estadual [...]" a solução contra os "professores vagabundos [...]" que discutem temas considerados "ideológicos" seria "[...] porrada a torto e a direito em todo o mundo"3; ou, ainda, nas frequentes declarações do Presidente da República e de seus ministros, tais como: a afirmação de que será realizada uma "Lava Jato na Educação" para investigar os gastos e desvios com "propaganda ideológica", a declaração de que pretendem "banir Paulo Freire do MEC" e mudar o patrono da educação, ou, mais recentemente, a "denúncia" de que existem plantações de drogas ilícitas em Universidades Federais. ${ }^{4}$

Esses exemplos nos mostram que além de fragmentado e descolado da realidade, o pensamento sectário é violento. Violento por promover o ódio, disseminar mentiras e incitar a violência física. Violento porque culpa o outro pela sua desumanização, por seu desamor. "Para os opressores [...] são sempre os oprimidos que os desamam. São sempre eles os 'violentos', os 'bárbaros', os 'malvados', os 'ferozes', quando reagem à violência dos opressores (FREIRE, 2017, p. 59). Violentos são eles, os sectários, que desumanizam a si e aos outros.

João Colares da Mota Neto, pesquisador que se dedicou a compreender a constituição do pensamento (des)colonial na América Latina a partir de Freire e Fals Borda, contextualiza nosso continente em um "estado de solidão", que nos foi historicamente imputado pelos colonizadores (MOTA NETO, 2016). Essa solidão, que há séculos contribui para o silenciamento dos nossos saberes, nossas culturas e nossas lógicas de pensamento, se manifesta na proposta da Escola sem Partido e nas ações daqueles que, desumanamente, defendem-na. Essa forma de desumanizar não é em nada original, ela é a nova cara

\footnotetext{
2 Disponível em: g1.globo.com/sc/santa-catarina/eleicoes/2018/ noticia/2018/10/29/deputada-estadual-do-psl-eleita-por-sc-incita-alunosa-filmar-e-denunciar-professores.ghtml. Acesso em 02 dez. 2019.

3 Disponível em: www.sinprors.org.br/comunicacao/noticias/justicamanda-tirar-da-internet-ofensas-a-professores-e-estudantes-do-rosario/. Acesso em 02 dez. 2019.

4 Disponível em: oglobo.globo.com/brasil/bolsonaro-defende-lava-jatoda-educacao-preve-greves-contra-investigacoes-23498200, https:// oglobo.globo.com/sociedade/bolsonaro-diz-que-vai-mudar-patronoda-educacao-brasileira-titulo-conferido-paulo-freire-23630439, https:/ g1.globo.com/educacao/noticia/2019/11/22/ministro-diz-que-haplantacoes-de-maconha-em-universidades-reitores-criticam-ataques-eretorica-agressiva.ghtml. Acesso em 02 dez. 2019.
}

da colonialidade; ou seja, vemos no descrédito à educação e no projeto Escola sem Partido a reprodução da "ordem opressora" que, muitas vezes, faz com que os oprimidos exerçam a violência de forma horizontal, agredindo a si mesmos em nome dos opressores (FREIRE, 2017, p. 68).

Emerge na escola um discurso no qual as formas de pensar, os tempos, os diferentes olhares sobre o mundo são ignorados, sendo considerada apenas uma pequena parte da forma eurocêntrica e ocidentalizada de conceber a realidade. Vemos um discurso que se opõe tanto à cultura popular quanto ao conhecimento "consolidado", que ataca o pensamento científico, constituindo-se entre fragmentos da racionalidade moderna e da ideologia inquisitória. É ela que determina o que e como deve ser aprendido, que delimita a forma como vemos o mundo.

Como alternativa ao esvaziamento promovido por esse pensamento colonializado e sectário, Neto (2016) enfatiza a importância de se estabelecer um diálogo com "formas outras" de conhecimento, que possibilitem novas maneiras de pensar o mundo a partir daquilo que o pesquisador chama de "epistemologia de fronteira", ou seja, uma forma de perceber o mundo elaborada a partir da interlocução crítica entre distintas concepções da realidade. Essa "epistemologia de fronteira", que está presente em Pedagogia do oprimido, pode ser facilmente encontrada nas práticas de educação popular, mas tende a ser mantida cada vez mais distante do cotidiano escolar e das políticas públicas,

\footnotetext{
Por isso é que não podemos, a não ser ingenuamente, esperar resultados positivos de um programa, seja educativo num sentido mais técnico ou de ação política, se, desrespeitando a particular visão do mundo que tenha ou esteja tendo o povo, se constitui uma espécie de invasão cultural, ainda que feita com a melhor das intenções. Mas “invasão cultural” sempre (FREIRE, 2017, p. 119).
}

Invasão cultural porque culpa o próprio povo, sua cultura e sua história pelos "fracassos" da educação nacional. Invasão cultural porque é singular em forma e conteúdo. É invasão cultural porque, por meio dessa falsa ausência ideológica, cujo objetivo fundamental “[...] mesmo que dele não estejam advertidos muitos dos que a realizam, seja dificultar, em tudo, o pensar autêntico" (FREIRE, 2017, p.89), impõe a cultura do silêncio e auxilia o processo de reprodução da dualidade existencial presente tanto nas novas diretrizes educacionais, quanto nos oprimidos que delas resultam e resultarão. Essa dualidade é representada pela introjeção do opressor, de seus interesses e suas visões de mundo nos oprimidos, que a reproduzem muitas vezes, sem perceber. Essa é a matriz da estrutura opressora: reproduzir a consciência colonizada por meio da autodesvalia, da descrença em si 
mesmos que, ao mesmo tempo, ocasiona a coisificação das pessoas e é ocasionada por ela.

Entretanto, esse ciclo não é eterno. A desumanização, apesar de fato histórico, não é nossa vocação histórica. "Na verdade, se admitíssemos que a desumanização é vocação histórica dos homens [seres humanos], nada mais teríamos a fazer, a não ser adotar uma atitude cínica ou de total desespero" (FREIRE, 2017, p. 40-41). Não haveria, neste caso, razão para reler Freire ou escrever este artigo. Se após 50 anos discutimos Pedagogia do oprimido é porque concordamos que a desumanização não é "destino dado”, ela é passível da transformação revolucionária.

\section{A SUPERAÇÃo DA REPARAÇÃo NA EJA: UMA REVOLUÇÃO CULTURAL}

A experiência de Angicos, os Círculos de Cultura, o Movimento de Educação de Base e as demais formas de organização popular com caráter pedagógico que se desenvolveram por todo o país no início da década de 1960 são exemplos daquilo que Freire chama de "revolução cultural". Essa revolução, como já mencionamos, estava inserida em um movimento global que levou as elites opressoras a se organizarem e deflagrarem, em diversos países latino-americanos, golpes civil-militares. No Brasil, o Golpe de 1964 fez com que Freire e seu método fossem "erradicados" não apenas das políticas educacionais, mas dos limites geográficos do nosso território - o que levou o educador ao Chile e à escrita de Pedagogia do oprimido.

$\mathrm{Na}$ segunda década do século XXI, o Brasil vive novamente um momento de efervescência de agendas minoritárias que, apesar de não se configurar como uma "revolução", leva estas mesmas elites a se mobilizarem e direcionarem o país às tendências mundiais neoconservadoras, limitando o debate político a uma luta entre o "bem" e o "mal" na qual Freire é, mais uma vez, desacreditado e tem seus princípios pedagógicos "exilados" do discurso oficial e das políticas educacionais. Entretanto, como a história mostrou, o exílio foi fundamental para que as ideias do autor se complexificassem, para que seu pensamento se tornasse universal e para que o "menino pernambucano" se tornasse um "ser do mundo".

A partir da perspectiva da revolução, possivelmente, uma das perguntas mais óbvias que poderíamos fazer a respeito de Freire e seus exílios seja: o que seria a EJA hoje se o Programa Nacional de Alfabetização, comandado por Paulo Freire, não tivesse sido interrompido em 1964? Não é possível responder a essa indagação, mas gostaríamos de trazer alguns dados que nos permitirão, ao menos, problematizar porque ainda existe a necessidade de alfabetizar adultos hoje.
As pesquisas estatísticas revelam dados que nos parecem interessantes para essa discussão: o primeiro é que, em números percentuais, o maior avanço na alfabetização de jovens e adultos brasileiros no século XX foi, justamente, entre as décadas de 1950 e 1960, quando a taxa de analfabetismo caiu de $50,6 \%$ da população para 39,7\% (INEP, s/a). Essa redução percentual não representou uma queda em números absolutos, mas, ainda assim, fez com que no decorrer da década de 1950 fosse registrado o menor crescimento no número de jovens e adultos não alfabetizados ${ }^{5}$ do século. $\mathrm{O}$ segundo é que, apesar dessa taxa estar decrescendo, o número absoluto de analfabetos cresceu no país ao longo das oito primeiras décadas do século XX, sendo reduzido apenas após a redemocratização. $\mathrm{O}$ terceiro dado é que, nas últimas duas décadas, conforme o número de jovens e adultos analfabetos diminui, o número de idosos analfabetos aumenta: enquanto o percentual de jovens entre 15 e 25 anos não alfabetizados é de 7,5\%, entre idosos com mais de 60 anos a taxa é superior a $20 \%$. E o quarto e último dado que consideramos relevante é que, apesar do número de matrículas na EJA não ter apresentado oscilações nos últimos anos (IBGE, 2018), o número de jovens entre 15 e 25 anos matriculados na modalidade aumentou.

Ou seja, tendo em vista a obrigatoriedade da educação para crianças e adolescentes a partir da Constituição Federal de 1988 e o elevado índice de matrículas (ambos superiores a 90\%) na educação fundamental de pessoas de 6 anos de idade ou mais nos censos de 2000 e 2010, é possível inferir que a educação de jovens e adultos está, por um lado, garantindo a continuidade de estudos de educandos que, apesar de alfabetizados, não concluíram seus estudos, enquanto, por outro lado, segue (re)produzindo a lógica excludente que não permitiu que adultos e idosos se alfabetizassem na "idade certa". Isso significa, na prática, que a função reparadora da EJA não está, de fato, atingindo as crianças, jovens e adultos que foram privados da educação ao longo do século XX. Significa que a dívida histórica com esses oprimidos não está sendo reparada.

Segundo a legislação vigente, a EJA tem função reparadora, equalizadora e qualificadora para aqueles que não tiveram acesso à educação na idade certa; entretanto, cada vez mais vemos jovens em idade escolar optando por essa modalidade de ensino (ou sendo encaminhados a ela). Analisando os dados disponibilizados pelos Censos Escolares de 2014, 2015 e 2017, percebemos que na medida em que os índices de distorção idade/série caem,

\footnotetext{
${ }^{5}$ Conforme os dados do Censo Demográfico disponibilizados pelo INEP (s/a, p. 06) na "Tabela 2 - Analfabetismo na faixa de 15 anos ou mais - Brasil - 1900/2000", em 1950 o número absoluto de brasileiros não alfabetizados era 15.272 milhões e em 1960 o número subiu para 15.964 milhões.
} 
as taxas de migração para EJA aumentam. Ou seja, para alunos/as cuja sala de aula tradicional desperta pouco interesse e parece tão distante de suas realidades, a EJA surge como uma alternativa para permanecer estudando.

A EJA, cuja proposta político-pedagógica sempre esteve ligada à Educação Popular, pode constituir-se de fato como alternativa para jovens enquanto uma ferramenta para a revolução cultural, na qual "[...] os oprimidos vão desvelando o mundo da opressão" e enfrentando a "cultura da opressão". (FREIRE, 2017, p. 57) Entretanto, atentamos para o fato de que há mais de 11 milhões de brasileiros e brasileiras que continuam "não sabendo ler nem escrever um bilhete simples no idioma que conhece [m]"6 e para o compromisso não apenas com esses sujeitos, mas com todos aqueles que ensinados a ler a palavra, foram e/ou estão sendo privados de ler o mundo.

Por isso, o último dado que gostaríamos de apresentar, na perspectiva da revolução cultural, diz respeito às pessoas que, tendo passado pelo processo de alfabetização, não conseguem compreender o que leem ou o que escrevem. Conforme o Indicador de Alfabetismo Funcional (INAF), pesquisa realizada comjovens e adultos com idades entre 15 e 64 anos, $64 \%$ dos brasileiros nesta faixa etária apresentam dificuldade no uso cotidiano da leitura e da escrita ou na interpretação daquilo que leem. Essa dificuldade não está diretamente relacionada com o nível de instrução dos entrevistados, mas com o propósito político-pedagógico da formação que tiveram. Afirmamos isso porque, ainda de acordo com o INAF, apenas $34 \%$ das pessoas que atingem o nível de ensino superior podem ser consideradas alfabetizadas proficientes, ou seja, possuem o domínio da compreensão e da interpretação de textos e resolvem problemas matemáticos envolvendo múltiplas etapas (IPM, 2018).

A função reparadora da EJA, portanto, está para muito além da alfabetização de jovens, adultos e idosos. A função reparadora está, justamente, na capacidade de ler o mundo, que, como já nos alertou Freire (2017), precede a leitura da palavra. Essa é a grande revolução cultural que o autor propôs: compreender, por meio da alfabetização, a história como possibilidade e não como destino dado desde sempre e para sempre. A revolução de Pedagogia do oprimido está na radicalidade com a qual Freire distingue mudanças meramente paliativas de transformações mais profundas na estrutura da sociedade.

Não podemos desmerecer medidas que melhorem a vida das pessoas, mas, por outro lado, também não podemos perder de vista aquilo que acreditamos ser uma sociedade justa, na qual todos tenham direito a uma vida digna. Não é difícil perceber que estamos longe disso. Daí

\footnotetext{
${ }^{6}$ Definição de analfabeto empregada pelo IBGE.
}

a necessidade da utopia, como aquilo que nos dá a direção, que nos faz caminhar e agir. Daí também a necessidade de relermos e reinventarmos novas pedagogias dos oprimidos.

\section{CONSIDERAÇÕES FINAIS}

Ao finalizarmos nossa reflexão, nos deparamos com a realidade de que, ainda hoje, vivemos em um país onde o acesso e a permanência no sistema público de educação são privilégios inalcançados por milhões de pessoas. As políticas públicas e as práticas da/na educação de jovens e adultos estão inseridas na dinâmica dos movimentos globais, do capital, do contexto sócio histórico de nosso país, da conquista de Direitos Humanos, do trabalho e das novas formas de convivência social e comunitária. Estão inseridas nas fronteiras epistemológicas da (des)colonialidade. Ou seja, nas tramas da história, na justaposição das tensões entre medidas conservadoras e libertadoras.

Neste contexto, a Educação Popular constitui-se como um espaço legítimo de (des)colonização dos corpos e das mentes, uma vez que ela é gerada, problematizada e reformulada a partir de práticas sociais locais (STRECK, 2009). Quer dizer, ela nasce e se desenvolve a partir da e na relação entre educadores/as, intelectuais e classes populares comprometidas com a transformação da realidade por meio da educação. Na nossa história, essas relações foram e ainda são profundamente marcadas pela ação político-existencial de Paulo Freire e em especial pela Pedagogia do oprimido, pois a obra é a síntese de iniciativas contra-hegemônicas de educação, nas quais o conhecimento é produzido com e para a população.

Apesar de verificarmos experiências inovadoras para a educação ética e politicamente comprometida de jovens e adultos, como as propostas da CLADE, não podemos permitir que a modalidade deixe de cumprir com sua função reparadora, que, como mostramos, está para muito além da alfabetização daqueles que não sabem ler e nem escrever. É preciso que problematizemos a EJA como uma possibilidade de educação para todos e todas, em qualquer idade de suas vidas, que desejem descobrir novas leituras de mundo em seus processos permanentes de humanização (ROSA, 2017). E, ao problematizarmos esse processo de humanização, precisamos problematizar o papel do/a professor/a que também está se humanizando.

Devemos lembrar que em seus processos de humanização, professores e alunos estão em constante tensão com a possibilidade de desumanização e, por isso, os educadores/as tem a responsabilidade de problematizar, de pensar junto com seus educandos. Em tempos nos quais as informações são abundantes e as problematizações escassas, a educação bancária parece estar retornando com 
força para as pautas educacionais e para as salas de aula. Neste contexto, encerramos nosso texto com uma frase de Freire que merece ser lembrada: 'Nenhuma 'ordem' opressora suportaria que os oprimidos todos passassem a dizer: 'Por quê?'” (FREIRE, 2017, p. 106).

\section{REFERÊNCIAS}

APPLE, Michael. Educando à direita: mercados, padrões, Deus e desigualdade. São Paulo: Cortez/Instituto Paulo Freire, 2003. https://doi.org/10.1590/s0101-73302003000300016

APPLE, Michael. Para além da lógica do mercado: compreendendo e opondo-se ao neoliberalismo. Rio de Janeiro: DP\&A Editora, 2005.

APPLE, Michael. Produzindo diferença: neoliberalismo, neoconservadorismo e a política de reforma educacional. Revista Linhas Críticas, n. 21, v. 46, p. 606-644. Disponível em: http://www.redalyc.org/articulo.oa?id=193543849005. Acesso em: 29 mar. 2019. https://doi.org/10.26512/ lc.v21i46.4684

CALVINO, Ítalo. Por que ler os clássicos. São Paulo: Companhia das Letras, 1993.

CLADE. Consulta Ampliando Voces: La educación de personas jóvenes y adultas desde la mirada de sus sujetos. Oficina Campaña Latinoamericana por el Derecho e la Educación: São Paulo: 2017. Disponível em: https://pt.scribd. com/document/356101490/Consulta-AMPLIANDO-VOCESLa-Educacion-de-Personas-Jovenes-y-Adultas-desde-lamirada-de-sus-sujetos. Acesso em: 29 mar. 2019. https://doi. org $/ 10.35376 / 10324 / 35358$

FREIRE, Paulo. Pedagogia do Oprimido. Rio de Janeiro: Paz e Terra, 2017.

FREIRE, Paulo. Pedagogia da Esperança: um reencontro com Pedagogia do oprimido. Rio de Janeiro: Paz e Terra, 2018. https://doi.org/10.22294/eduper/ppge/ufv.v9i3.1108

GADOTTI, Moacir. Paulo Freire e a Educação Popular. Proposta: Revista trimestral de Debate da FASE, n.113, p. 2127, jul./set., 2007.

INEP. Instituto Nacional de Estudos e Pesquisas Educacionais Anísio Teixeira. Mapa do Analfabetismo no Brasil. Brasília: Ministério da Educação, s/a. https://doi.org/10.1590/s2176$6681 / 371614642$

IPEM. Instituto Paulo Montenegro: ação social do IBOPE. Indicador de Analfabetismo Funcional: INAF Brasil 2018 - resultados preliminares. INAF Brasil, 2018. Disponível em: https://drive.google.com/file/d/1 ez6jrlrRRUm9JJ3MkwxEUffl tjCTEI6/view. Acesso em: 29 mar. 2019.

MOTA NeTO, João. C. Por uma Pedagogia Decolonial na América Latina: Reflexões em torno do pensamento de Paulo Freire e Orlando Fals Borda. Curitiba: CRV, 2016. https://doi. org/10.17227/folios.48-8131
ROSA, Carolina Schenatto da. Toda a idade é certa se a educação é ao longo da vida: horizontes de(s)coloniais para política de educação de jovens e adultos na América Latina. 2017. 139f. Dissertação (Mestrado em Educação) - Programa de Pós-Graduação em Educação, Universidade La Salle, Canoas, 2017. https://doi.org/10.24115/s24466220201621118p.36-50

STRECK, Danilo R. Uma pedagogia em movimento: os movimentos sociais na obra de Paulo Freire. In: MAFRA, Jason et al. Globalização, Educação e Movimentos Sociais: 40 anos da Pedagogia do Oprimido. São Paulo: Editora do Instituto Paulo Freire-Esfera, 2009. p. 63-72. https://doi. org/10.1590/1981-7746-sol00188

Recebido em: 30/03/2019.

Aprovado em: 30/10/2019.

Publicado em: 21/12/2019.

Endereço para correspondência:

Danilo R. Streck

Av. Unisinos, 950 - Cristo Rei

93022-750, São Leopoldo, RS, Brasil

Autores:

DANILO R. STRECK

Doutor em Educação pela The State University of New Jersey, Rutgers, New Brunswick, NJ, Estados Unidos. Professor do Programa de Pós-Graduação em Educação da Universidade do Vale do Rio dos Sinos.

Orcid: http://orcid.org/0000-0001-7410-3174

E-mail: dstreck@unisinos.br

Carolina Schenatto da Rosa

Mestre em Educação pela Universidade La Salle, Canoas/RS, Brasil. Doutoranda em Educação pela Unisinos, São Leopoldo, RS, Brasil.

Orcid: http://orcid.org/0000-0001-5021-3782

E-mail: carol-510@hotmail.com 